\title{
Design of CPW Antenna for Future Wireless Application
}

\author{
S.Monisha ${ }^{1}$, U.Surendar ${ }^{2}$ \\ PG Scholar, Department of ECE, K.Ramakrishnan College of Engineering, Trichy, India ${ }^{1}$ \\ Assistant Professor, Department of ECE, K.Ramakrishnan College of Engineering, Trichy, India ${ }^{2}$
}

\begin{abstract}
A hexagonal shaped Co-Planar Waveguide (CPW) fed antenna is proposed with Electric Field Coupled Resonator (ELC) structure for LTE application. The antenna consists of hexagonal slot in the patch with meta-material structure at the centre. Using ELC structure, the impedance matching is occurred efficiently. The frequency band covered by this proposed antenna is $2.6 \mathrm{GHz}$ with the return loss of $-23 \mathrm{~dB}$. The total size of the antenna is $28 \times 31 \times 1.6 \mathrm{~mm}^{3}$. The dielectric constant used for this antenna is FR4 substrate. The optimal VSWR and Radiation pattern characteristics are obtained for this frequency band. The proposed antenna is designed and simulated using High Frequency Structure Simulator (HFSS).
\end{abstract}

Keywords: Coplanar Waveguide, Electric Field Coupled Resonator, Impedance Matching, Meta-Material, VSWR

\section{INTRODUCTION}

In recent days, Wireless communication plays a major role in communication systems. The total populations were connected with global audience through wireless communication. The lack of physical infrastructure makes the wireless communication desirable for wide applications. In wireless communication the great role has been made by antenna [15]. Nowadays the antenna with broad bandwidth and smaller size were the difficult challenges in the wireless area. And also wearable antenna is also used for biosignal monitoring [11] (bio-signal communication). The use of metamaterial technology has a great influence in antenna. By using the ANN technology, the Microstrip patch antenna can be analyzed [1]. There is an increase in bandwidth of antenna by increased substrate thickness and decreased dielectric substrate [3]. Complementary Split Ring Resonator (CSRR) [7], Split Ring Resonator (SRR) [16] and Electric Field Coupled Resonator (ELC) [14] are some of the structures of metamaterial. Wide bandwidth and multiband characteristics can be achieved by using CPW structure [6]. The narrow bandwidth [12] is used for wireless application. The slits loaded in the ground plane offers better impedance matching [2]. The ELC provides negative permeability characteristics due to its stop band behavior. Since the planar inverted F antenna (PIFA) was analyzed in compact area, this can be greatly utilized in mobile communication [19]. The frequency bands in the range from 1.71 to $2.69 \mathrm{GHz}$ were referred for LTE communication. For LTE communication, the antenna should hold the following properties such as impedance bandwidth, stable gain and omnidirectional radiation pattern [4]. The antenna design for $\mathrm{mm}$ wave range was discussed [13]. The stubs were introduced for enhance the impedance matching at [20]. To meet the LTE communication the combined type (Low wide-band antenna and high wide-band antenna) were preferable [9]. The meandered structure used to achieve the LTE lower band and coupling feed enhances the impedance matching [5]. The data exchanging capabilities and higher data transmission rate were improved by utilizing MIMO antenna [9].Folded Lshaped antenna with driving strip as well as short strip coupled together with matching circuit were desirable to achieve LTE communication bands [10] Coplanar Waveguide fed is used for most of the antenna design for many applications [18]. This can be acted as a ground plane with two conductors present between the patch [17]. Totally including ground and patch three conductors are present at the top of the substrate. Varying the parameters to obtain UWB applications for this same antenna [21]. GPS works in two technology bands for obtaining the global positioning [22].

\section{ANTENNA DESIGN}

The proposed antenna design step is obtained from conventional hexagonal patch antenna for LTE application explained in Figure 1. The conventional patch antenna with CPW fed does not resonate any of the frequency band, after implementing hexagonal slot with ELC material at the center of the patch gives a resonant frequency for LTE application. Configuration (a) is the conventional hexagonal patch antenna and it does not resonant any frequency band. Configuration (b) is the hexagonal slot in the hexagonal patch antenna and it obtains frequency bands as $2 \mathrm{GHz}$ and 4.5 $\mathrm{GHz}$ with impedance mismatching. Configuration (c) is the final proposed antenna with the metamaterial structure and it resonant a frequency as $2.6 \mathrm{GHz}$ for LTE application. 
Vol. 8, Issue 5, May 2019

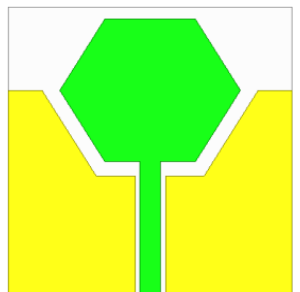

(a)

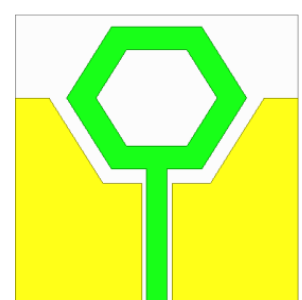

(b)

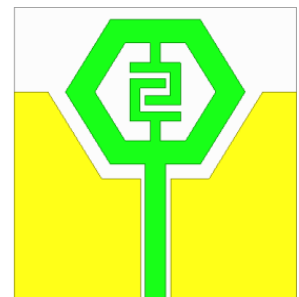

(c)

Figure 1: Design steps of proposed antenna (a) Conventional antenna (b) Hexagonal slot(c)With ELC

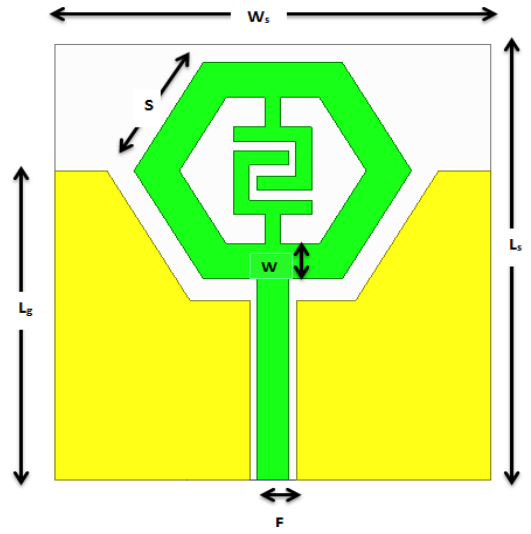

Figure 2: Design of Hexagonal shape with ELC structure antenna.

This antenna is designed and simulated using the finite element method software High Frequency Structure Simulator (HFSS). The dimensions of this prototype antenna are detailed in the Table 1. The final design of the antenna geometry is at Figure 2.

Table: 1 Details of Dimensions of Antenna

\begin{tabular}{|c|c|}
\hline Parameter & Dimensions in $\mathbf{~ m m}$ \\
\hline $\mathrm{W}_{\mathrm{s}}$ & 28 \\
\hline $\mathrm{L}_{\mathrm{s}}$ & 31 \\
\hline $\mathrm{L}_{\mathrm{g}}$ & 22 \\
\hline $\mathrm{W}$ & 1.5 \\
\hline $\mathrm{F}$ & 2 \\
\hline $\mathrm{S}$ & 5.1 \\
\hline
\end{tabular}

Table 1 describes the dimensions of the prototype antenna. Figure 2 geometry is the top view of the proposed antenna.

\section{SIMULATION RESULTS}

Each configuration in Figure 1 gives different frequency band and gain. The simulation results of the configurations are geometrically represented in Figure 3. The conventional antenna does not obtain any frequency band. So that slot is engraved from the hexagonal patch and it gives frequency bands as $2 \mathrm{GHz}$ and $4.6 \mathrm{GHz}$ with impedance mismatching. For obtaining impedance matching and the antenna becomes more efficiency, the ELC structure is inserted in the center of the patch and it is said to be efficient antenna. The proposed antenna resonant at the frequency band of $2.6 \mathrm{GHz}$ with better impedance matching. The impedance bandwidth of $-10 \mathrm{~dB}$ at $2.6 \mathrm{GHz}$ is $134.3 \mathrm{MHz}$.

The ratio of maximum to minimum voltage of the antenna is said to be Voltage Standing Wave Ratio (VSWR). VSWR $<2$ is optimum for most of the applications in the Microstrip patch antenna. This proposed antenna is also contains the VSWR value as under the value of 2. This parameter can be calculated by the formula is given in eqn.1.1

$$
V S W R=\frac{\|1+\Pi\|}{\|1-\Pi\|}
$$

For this antenna's resonant frequency $2.6 \mathrm{GHz}$, the VSWR value is 1.1414 . That VSWR geometry is shown in figure 4. Figure 5 illustrates the radiation pattern of the proposed antenna. For this resonant frequency, omnidirectional pattern obtained for E-plane and bi- directional pattern obtained for H-plane. This E-plane and H-plane of this proposed antenna is well suitable for LTE application. 
Vol. 8, Issue 5, May 2019

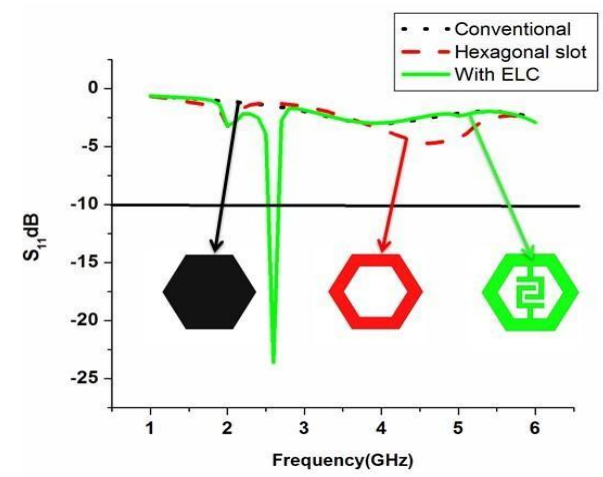

Figure 3: Simulated $\mathrm{S}_{11}(\mathrm{~dB})$ results of three configuration antennas

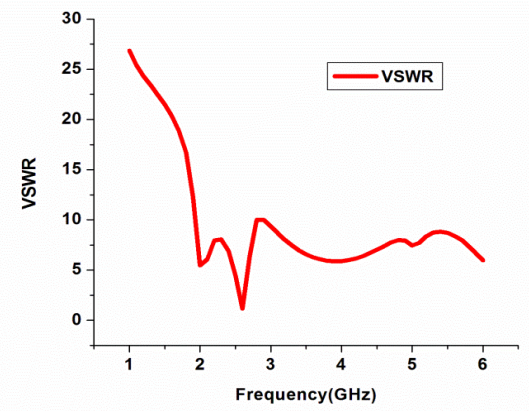

Figure 4: VSWR for the simulated antenna

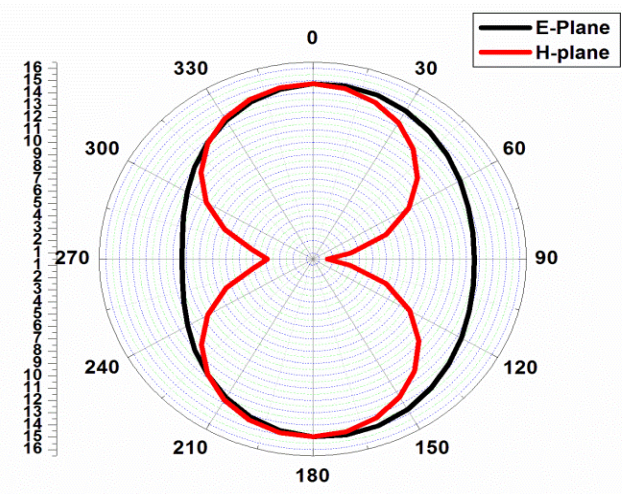

Figure 5: Radiation pattern for $2.6 \mathrm{GHz}$

Figure 6 shows the total gain of the proposed antenna. The total gain of the antenna is $1.0045 \mathrm{~dB}$; the appropriate gain is obtained for this prototype antenna.
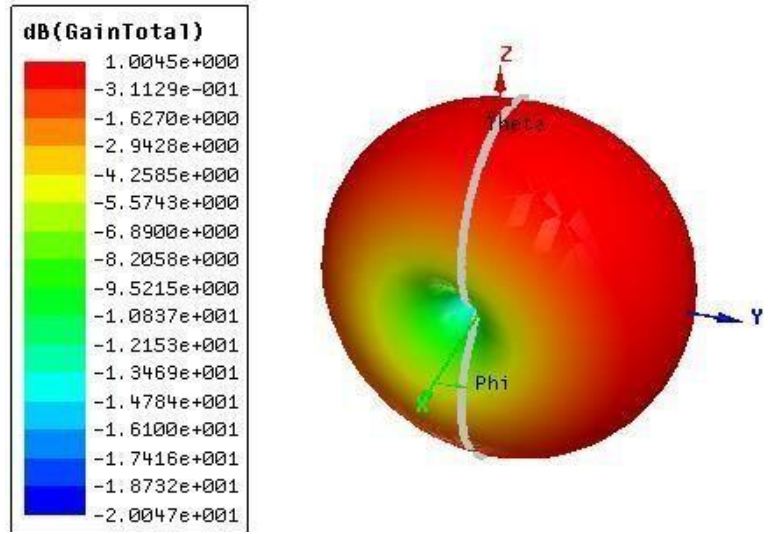

Figure 6: Total gain $(\mathrm{dB})$ of the proposed antenna 

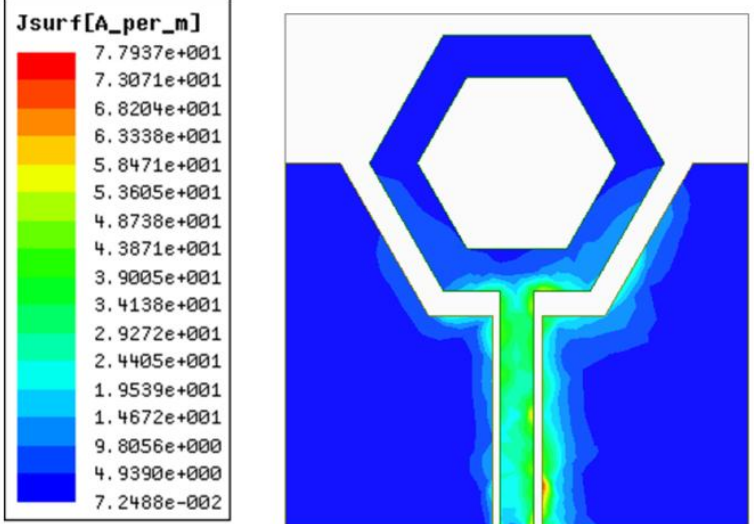

(a)

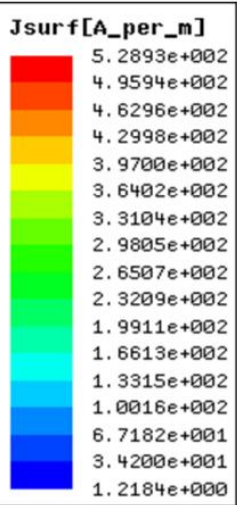

$1.2184 e+000$

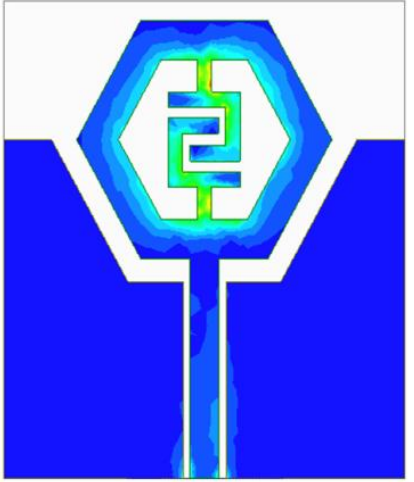

(b)

Figure 6: The Current distribution of (a) Unloaded ELC (b) Loaded ELC of the proposed antenna

Figure 6(a) and 6(b) are the current distribution of the proposed antenna. Figure 6(a) is the current distribution of unloaded ELC structure in antenna. Figure 6(b) is the current distribution of Loaded ELC structure in the proposed antenna. In configuration (b) the current distribution is mostly occurred in ELC structure

\section{SIMULATION RESULTS}

\subsection{Parametric study of length of the ground:}

The CPW fed is used for the proposed antenna. Figure 7 describes simulated result of the various length of ground plane of this antenna. The full CPW ground gives multiple band of the resonant frequencies are $2 \mathrm{GHz}$ and $5.6 \mathrm{GHz}$. For half CPW ground gives a single band at $2.6 \mathrm{GHz}$, but the impedance matching is not appropriate. Then finally at $\mathrm{L}_{\mathrm{g}}=22 \mathrm{~mm}$, for that same frequency band $2.6 \mathrm{GHz}$ the better impedance matching is obtained and it is suitable for Future Wireless application.

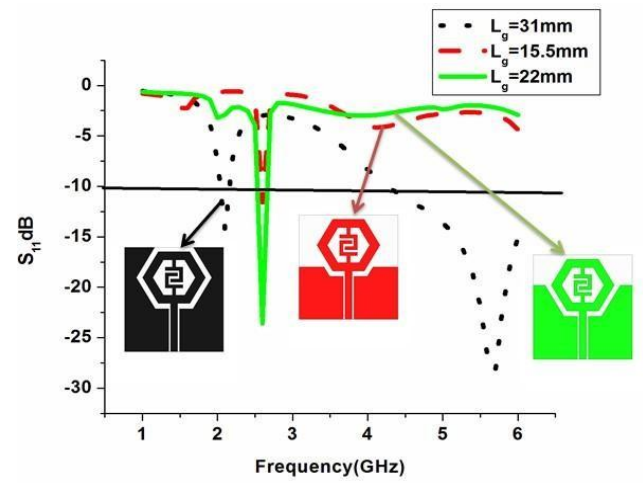

Figure 7: Parametric study of length of the ground

\subsection{Capacitive outcome of ELC:}

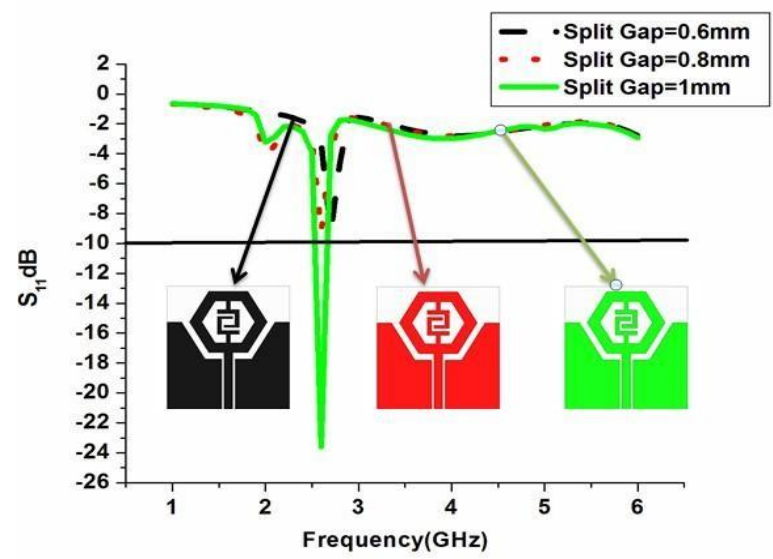

Figure 8: Capacitive outcomes for various split gap 
Vol. 8, Issue 5, May 2019

The ELC is under metamaterial structure, that ELC is loaded in this patch of the antenna. The metallic portion of the ELC is considered as the inductance (L) and the gap between the metallic portions are considered as the capacitance (C). By varying the split gap of the ELC, the outcome of ELC performance in the antenna can be analyzed. The split gap is varied from smaller value to higher value. For the higher value of split gap good impedance matching is obtained. The performance is illustrated in Figure 8.

\section{CONCLUSION}

In this paper, the hexagonal shaped CPW fed with ELC structure antenna is simulated using HFSS. The size of the antenna is compact and well suited for future wireless application. The resonant frequency of the antenna is $2.6 \mathrm{GHz}$ with the return loss of $-23 \mathrm{~dB}$. The Gain, radiation pattern and VSWR of this antenna is well suitable for LTE application. The good impedance matching obtained by this proposed antenna.

\section{REFERENCES}

[1]. Anil Kumar, B Murugeshwari, S Raghavan, Design of Substrate Integrated Waveguide Power Divider and Parameter optimization using Neural Network. IOSR Journal of Electronics and Communication Engineering (IOSR-JECE), 13(1): 37-43 (2018).

[2]. Amir Siahcheshm, Javad Nourinia, Yashar Zehforoosh, Bahman Mohammadi, "A Compact Modified Triangular CPW- Fed Antenna With Multioctave Bandwidth", Microwave And Optical Technology Letters ,Vol. 57, No. 1, January 2015.

[3]. Ashish Gupta, Raghvendra Kumar Chaudhary, "A Compact CPW-Fed Wide band Metamaterial Antenna with EBG Loading" Microwave And Optical Technology Letters, Vol. 57, No. 11, November 2015.

[4]. Botao Feng, Sixing Yin, Shufang Li," A Planar-Printed E- Shaped Omnidirectional Magneto-Electric Dipole Antenna For WWAN/LTE Applications", Microwave And Optical Technology Letters, Vol. 56, No. 8, August 2014.

[5]. Cheng-Chi Yu, Jiin-Hwa Yang, Chang-Chih Chen, "A Compact Internal Antenna For LTE/WWAN Mobile Phone Applications", Microwave And Optical Technology Letters, Vol. 58, No. 8, August 2016.

[6]. Dinesh, R., V. K. T. Vinod, V. P. Sarin, V.A. Shameena, P. Mohanan, "Asymmetrical Grounded CPW-Fed Antenna For WLAN Applications", Microwave And Optical Technology Letters, Vol. 55, No. 11, November 2013.

[7]. Gayathri R, and Maheswari M. Design And Fabrication Of Dual Band RFID Antenna Using Hybrid Coupler With CSRR. Pakistan Journal of Bio Technology, 14(1): 87-89(2017).

[8]. Kin-Lu Wong, Chih-Yu Tsai," Combined-Type Triple- Wideband LTE Tablet Computer Antenna", Microwave And Optical Technology Letters ,Vol. 57, No. 5, May 2015

[9]. Loghman Asadpor, Mirhamed Rezvani," Multiband microstrip MIMO antenna with CSRR loaded for GSM and LTE applications”, Microwave and Optical Technology Letters 2018;60:3076-3080.

[10]. Li Jiu-Sheng, Fan Qing-Hua, and Sun Jian-Zhong," Coupled- Fed Antenna With A Matching Circuit For Small Size LTE/WWAN Tablet Computer Application", Microwave And Optical Technology Letters, Vol. 58, No. 4, April 2016.

[11]. Monisha. S, and U.Surendar, A Survey on Wearable Antenna for ISM Band Application. IOSR Journal of Electronics and Communication Engineering, 49-54 ( 2018).

[12]. Muruganantham. T, Surendar U, and Balakumar A Dual Band Bandpass Filter With Sharp Passband Resonances Using Dual-Mode SIRs. International journal of microwave applications, 6(2): 18-21 (2017).

[13]. Praveena,S,B.Murugeshwari, U.Surendar R. Kayalvizhi, A Review on Antenna Design for Millimeter Wave range, IOSR Journal of Electronics and Communication Engineering, pp. 01-06, 2018.

[14]. Samson Daniel. R, Pandeeswari, and S Raghavan. Dual-band monopole antenna loaded with ELC metamaterial resonator for WiMAX and WLAN applications Applied Physics A 124 (18):1984-1987 (2018).

[15]. Samson Daniel.R Design and Simulation of Multiband CPW feed Ring Shaped Antenna for Wireless Applications. International Journal of Engineering Sciences \& Research Technology, 549-553(2014).

[16]. Thamil Selvi.N, P.N.Thiruvalar Selvam, S.P.K. Babu, R.Pandeeswari and R.Samson Daniel. A Broad-side coupled SRR Inspired CPW Fed Dual Antenna for WiMAX and Wave Applications", PIER C, 81:231 (2018).

[17]. Thamil Selvi. N, R. Pandeeswari and P.N. Thiruvalar Selvan, An Inset-fed Rectangular Microstrip Patch antenna with Multiple split Ring Resonator Loading for WLAN and RF-ID Applications, PIER C, 81:41-52 (2018).

[18]. Varikuntla Krushnakanth, B.Murugeshwari and Singaravelu Raghavan, "Design of a CPW Fed substrate integrated waveguide using Frequency selective surface. $11^{\text {th }}$ international Radar symposium India(IRSU'17), Bangalore, India (2017)

[19]. Won-Woo Lee and Cheol Yoon,"A Reconfigurable Antenna using Tuning Element for LTE applications" Microwave and Optical Technology Letters, Vol.57, N0.3, March 2015.

[20]. W. N. N. W. Marzudi, Z. Z. Abidin, S. H. Dahlan, Ma Yue, Raed A. Abd-Alhameed, M. B. Child, A Compact Orthogonal Wideband Printed MIMO Antenna for WiFi/WLAN/LTE Applications, Microwave and optical Technology Letters, Vol. 57,No. 7, July 2015.

[21]. V.Indhumathi,B.I.S.Ronica, "Design of Koch Fractal Patch Antenna For UWB Application" Proceedings of International Conference on Engineering Trends and Science \& Humanities(ICETSH-2015).

[22]. S Shabina, Smart Helmet Using RF and WSN Technology for Underground Mines Safety, Proceedings of International Conference on Intelligent Computing Applications, pp.305-309,2014.

[23]. Revathi, A Jeyalakshmi, C "Robust Speech Recognition in Noisy Environment using Perceptual Features and Adaptive Filters", Proceedings of 'International Conference on Communication and Electronics Systems (ICCES 2017), IEEE explore, pp.692-696, 2018.

[24]. Revathi, A Jeyalakshmi, C 2017, 'A challenging task in recognizing the speech of the hearing impaired using normal hearing models in classical Tamil language', Journal of Engineering research, vol.5 no.2, pp.110-128, June2017. 